\title{
PERFORMANCES DISCURSIVAS \\ DE UMA “BIXA TRAVESTY”: SOBRE CORPO, GENERO E IDENTIDADE EM LINN DA QUEBRADA
}

\section{PERFORMANCES DISCURSIVAS DE UNA "BIXA TRAVESTY": SOBRE EL CUERPO, GÉNERO E IDENTIDAD EN LINN DA QUEBRADA}

DISCURSIVE PERFORMANCES OF A “BIXA TRAVESTY”: ON BODY, GENDER AND IDENTITY IN LINN DA QUEBRADA

Danillo da Conceição Pereira Silva* Instituto Federal de Educação, Ciência e Tecnologia de Alagoas Universidade Federal de Sergipe

Emilly Silva dos Santos* Universidade Federal de Sergipe

\footnotetext{
RESUMO: Neste artigo, temos como objetivo oferecer uma reflexão teórico-analítica acerca das conexões entre corpo, gênero e identidade, a partir de uma visada performativa e queer de linguagem, conforme perspectivas da Linguística Aplicada Indisciplinar. Para tanto, além das discussões teóricas realizadas, analisamos três performances discursivas da artista e ativista social Linn da Quebrada, em entrevista concedida à revista brasileira Cult, em agosto de 2017. Em consequência do percurso empreendido, argumentamos que a desessencialização das referidas concepções se torna fundamental para desestabilizar efeitos de verdade

* Doutorando e Mestre em Letras/Estudos Linguísticos pelo Programa de Pós-Graduação em Letras da Universidade Federalde Sergipe (PPGL/UFS). Professor de Língua Portuguesa do Instituto Federalde Educação, Ciência e Tecnologia de Alagoas (IFAL), campus Santanado Ipanema. E-mail: danillosh@gmail.com.

* Mestranda em Letras/Estudos Linguísticos pelo Programa de Pós-Graduação em Letras da Universidade Federal de Sergipe(PPGL/UFS). E-mail: emillys@live.com.
} 
excludentes construídos, tensionados e contestados na/pela linguagem, além de fomentar sua potencialidade na aliança com ativismos sociais e acadêmicos engajados em favor das diferenças identitárias na modernidade recente.

PALAVRAS-CHAVE: Corpo. Gênero. Identidade. Performances discursivas queer. Linn da Quebrada.

RESUMEN: En este artículo, tenemos como objetivo ofrecer una reflexión teórico-analítica acerca de las conexiones entre cuerpo, género e identidad, a partir de una visión performativa y queer de lenguaje, según las perspectivas de la Linguística Aplicada Indisciplinar. Para ello, además de las discusiones teóricas realizadas, analizamos tres performances discursivas de la artista y activista social Linn da Quebrada, en una entrevista concedida a la revista brasileña Cult, en agosto de 2017. Como consecuencia del recorrido emprendido, argumentamos que la desencialización de las referidas concepciones se vuelve fundamental para desestabilizar efectos de verdad excluyentes construidos, tensados y contestados por el lenguaje, además de fomentar su potencialidad en la alianza con activismos sociales y académicos comprometidos en favor de las diferencias de identidad en la modernidad reciente.

PALABRAS-CLAVE: Cuerpo. Género. Identidad. Performances Discursivas Queer. Linn da Quebrada.

ABSTRACT: In this article, we aim to offer a theoretical-analytical reflection on the connections between body, gender and identity, from a performative and queer perspective of language, according to the perspectives of Indisciplinary Applied Linguistics. Therefore, in addition to the theoretical discussions, we analyzed three discursive performances by the artist and social activist Linn da Quebrada in an interview given to the Brazilian magazine Cult, in August 2017. As a consequence of the line of enquiry adopted, we argue that the de-essencializing of those concepts becomes fundamental to destabilize factual, constructive, tensioned and contested truth effects in language, as well as to foster its potentiality to form alliances with social and academic activism engaged in favor of identity differences in recent modernity.

KEYWORDS: Body. Gender. Identity. Linn da Quebrada. Queer Discursive Performances.

\section{INTRODUÇÃO}

Situando-nos nas fronteiras epistemológicas de uma Linguística Aplicada que se quer indisciplinar e ideológica (MOITA LOPES, 2006, p. 97), em aliança com os Estudos Queer, compreendemos que fazer pesquisa científica é, também, fazer política. Por isso, propomo-nos, neste artigo, a discutir noções que têm se mostrado fundamentais para o trabalho crítico de ativismos sociais e acadêmicos em favor das diferenças de gênero e sexualidade, partindo da voz de quem, no centro das mobilizações dessas políticas e possibilidades de subjetivação outras, tem legitimidade para dizer a si mesma e a sua causa, a a(r)tivista social brasileira Linn da Quebrada.

Assim, este trabalho é feito tecendo construtos teóricos que assumem (e, ao mesmo tempo, "riem" dessas categorias sérias ${ }^{1}$ ) a produção de identidades a partir de um viés performativo e que, justamente em razão disso, possuem grande potencial de desestabilização das perspectivas de sistemas normativos fixos para as possibilidades de ser e existir em corpo e gênero. Pensar as vivências da "modernidade recente" (RAMPTON, 2006, p. 110) e seu alto grau de reflexividade sob essa perspectiva nos permite, enquanto pesquisadorxs e ativistxs ${ }^{2}$ da pauta política aqui discutida, questionar retóricas, inclusive acadêmicas, que tomam marcadores sociais da diferença, a exemplo de corpo, raça, gênero e sexualidade, como elementos dados, realidades essenciais preexistentes à linguagem e que nela encontrariam, sob essa premissa neoplatônica, apenas produções especulares, encarnadas em diferentes construtos semióticos ou em fenômenos variáveis da língua.

\footnotetext{
${ }^{1}$ A exemplo do que faz Butler (2017) a respeito da categoria “mulher" enquanto sujeito político do feminismo.

${ }^{2}$ Neste texto, assumimos o emprego do "x" como possibilidade de intervenção no gênero gramatical das palavras, enquanto ação engajada no exercício de um ativismo linguístico (LAGARES, 2018) questionador frente ao masculinismo universalista na língua, agenciando, assim, imundícies verbais (BORBA; LOPES, 2018) que visem a flexibilizar as possibilidades de identificação na/pela língua, afirmando-a enquanto sistema heterogêneo e dinâmico, eminentemente social e atravessado por disputas ideológicas.
} 
Diante do lugar epistemológico e político aqui ocupado, salientamos que este artigo almeja atingir dois objetivos complementares, por um lado: a) contribuir para a ampliação das discussões acerca das noções de corpo, gênero e identidade, em perspectiva queer, pondo em diálogo, para tal, pensadorxs como Austin (1976), Butler (2003), Pennycook (2007) e Moita-Lopes (2013), dentre outras; e b) analisar a produção de desestabilizações dessas mesmas categorias, com base nos referencias acima mencionados, a partir das performances discursivas queer da ativista Linn da Quebrada, em entrevista concedida à revista brasileira Cult, em agosto de 2017.

Este estudo, portanto, estará disposto em três seções centrais. Na primeira delas, traçaremos uma contextualização do termo queer e do campo de estudos nomeado por esse insulto apropriado, apontando, assim, seu lugar nos debates contemporâneos de gênero. Posteriormente, discutiremos o caráter performativo da linguagem e a implicação dessa premissa na consideração das categorias corpo e identidade, evidenciando que as rupturas e tensões produzidas por essa opção epistemológica apontam para uma postura queer. Por fim, segundo as articulações propostas ao longo do trabalho, procederemos às análises das performances discursivas da referida transativista, intentando evidenciar seu potencial subversivo e transgressor, face a sistemas normativos que creem ser as identidades essências fixas, estáveis e bem delimitadas.

\section{O QUEER E A NORMA: CONTEXTUALIZANDO UMA EPISTEME DE RESISTÊNCIA}

Partindo de um ponto de vista sociohistórico do termo, podemos situar o queer ${ }^{3}$ como fruto da apropriação política de uma forma de insulto, em língua inglesa, para referir-se a um grupo de sujeitos desajustados, desviantes, estranhos, a fim de produzir sua afirmação, nomeando assim um movimento de resistência política, o movimento queer, no contexto dos Estados Unidos da América dos anos 1960. Tal estratégia de ocupação linguística, enquanto índice de uma ocupação de espaços políticos, emerge justamente sob o argumento do enfrentamento de multiformes violências, muitas, inclusive, segundo discute Miskolci (2016), inscritas nas práticas assimilacionistas e pouco contestatórias das normas corporais, sexuais e genéricas vigentes, implementadas pelos movimentos hegemônicos de liberação gay da época. Assim, o movimento queer se apresenta, no contexto das questões de gênero, como um modo de questionar posições que tendem a essencializar identidades e estabelecer fronteiras imóveis para seus limites.

Nesse contexto histórico de luta por direitos civis nos Estados Unidos, os movimentos sociais identitários, apesar de colocarem em xeque os padrões morais hegemônicos dos cidadãos de bem americanos (a exemplo do movimento negro, do movimento feminista e do homossexual), estavam imbricados em lutas políticas que visavam à libertação de uma categoria, assumindo, pois, tais categorias como dadas, unitárias e representativas de um feixe de caracteres facilmente determináveis. Uma vez sendo estas representativas de grupos historicamente submetidas a processos de marginalização e exclusão social, careciam então de uma ação libertadora que se encarnava na militância de tais movimentos em favor dos sujeitos lidos socialmente debaixo dessas etiquetas identitárias.

Essa concepção, no entanto, engendra uma constante exclusão, pois, uma vez promulgados padrões fixos para uma categoria identitária, são, consequentemente, estabelecidos regimes de vigilância sobre suas fronteiras, uma série de políticas de reconhecimento é posta em funcionamento, abrindo espaço, assim, para a exclusão, a hierarquização e a marginalização de determinadas formas de vida. Essa lógica é parte das tecnologias socias que buscam enquadrar cada pessoa em uma identidade, adequar cada corpo a um único gênero, isto é, produzir homens ou mulheres ideais, "pessoas normais" (MISKOLCI, 2016, p. 1112), as quais desempenham a idealizada e exigida coerência compulsória entre corpo, sexo, gênero e desejo, como nos alerta Bulter. Ainda nesse sentido, como nos adverte Trujillo (2015), e em consequência da breve incursão histórica empreendida nos parágrafos anteriores, a perspectiva queer traz consequências bastante potentes para os próprios movimentos sociais e políticas várias que se organizam em torno de sujeitos definidos e de identidades sexuais e de gênero bem delimitadas. Nas palavras da pesquisadora:

\footnotetext{
${ }^{3}$ Reconhecemos que, apesar de esta expressão corresponder a como ficaram nomeados os movimentos e as vertentes de estudos às quais nos referimos aqui, vale ressaltar a instabilidade dessa nomeação, uma vez que contestações de cunho decolonial apontam que talvez fosse mais adequado, inclusive por um sentido de coerência com a filosofia de base de tais movimentos, os sociais e os acadêmicos, adotar termos que tivessem o mesmo cunho vexatório e transgressivo, um palavrão injurioso, como é queer para o inglês, diante da moral hegemônica no léxico das línguas de cada região em que estes fossem implementados. Em espanhol, se tem falado, a título de exemplo, em estudos "transmaricabolos" (o equivalente a trans-viado-sapatão, em português). No caso do Brasil, Berenice Bento (2016) propõem falarmos em "estudos transviados".
} 
[...] os saberes queer questionam a suposta coerência de identidades gays, lésbicas e transexuais, tornando-as suspeitas, evidenciando e desmantelando os processos regulatórios de formação e categorização dos sujeitos. As práticas, histórias e experiências queer questionam os limites das identidades sexuais e de gênero, que não são homogêneas e fixas, e são atravessadas por outras. (TRUJILLO, 2015, p. 1536, tradução nossa)

Os movimentos queer, como aponta Miskolci (2016), questionam o argumento fundacional de que existam categorias identitárias que sejam dadas, fixas e fechadas. Assim, o queer emerge, quer como movimento social ou como vertente de estudos acadêmicos advindos de diferentes campos do conhecimento (hoje podemos falar em Linguística Queer, Criminologia Queer, por exemplo), um impulso crítico em relação às doutrinas essencialistas que fundamentam a ordem corporal, sexual e genérica contemporânea, sobretudo em Estados coloniais e neoliberais.

Posto isso, podemos entender que, enquanto a problemática dos movimentos identitários está na libertação das possibilidades de ser e existir como parte de um grupo de vivências viáveis e moralmente possíveis, a problemática do queer está no questionamento da legitimidade da norma que fundamenta e organiza o estado de coisas que torna válida a hierarquização das vidas e a produção de um espaço de abjeção, local ao qual a coletividade, o Estado, os cidadãos de bem, aqueles posicionados dentro dos modelos identitários inteligíveis decidem abandonar, nos sentidos mais práticos possíveis, aqueles que são considerados como uma ameaça à norma.

Ao nosso ver, do ponto de vista dos estudos queer, a consequência mais básica de validarmos o axioma de que nada preexiste ao discurso é a possibilidade de desnaturalizar e desessencializar instâncias postas como fixas, imutáveis, estáveis e sem anterioridades que as situem numa trajetória de coisas. Desse modo, conforme referido por Moita Lopes (2013), em ressonância ao pensamento de Foucault e Butler, advogamos que as identidades são parte dessas instâncias que são performatizadas por meio do discurso e, por isso, sujeitas às suas tensões, disputas e normas. Assim, pensamos que as identidades são produtos instáveis de performances discursivas que operam no interior de sistemas regulados, normatizados, os quais apesar de constranger por um sem-número de técnicas discursivas os indivíduos a ocuparem posições identitárias que correspondam a um modelo de sujeito (ou de sujeição) hegemônico, abrem, por sua própria natureza normativa, a possibilidade da fratura, da desregulação, ou seja, do descumprimento, muitas vezes paródico, dessa mesma norma. É dessa possibilidade que nascem as instabilidades e as rasuras, as torções das/nas categorias identitárias pretensamente fixas e homogêneas.

Nesse sentido, ao realizarmos uma incursão nos caminhos do pensamento foucaultiano, percebemos que, para o autor, a construção das subjetividades está intimamente relacionada às condições históricas em que essas são produzidas. Foucault, ao dizer que o sujeito "não é uma substância. É uma forma, e essa forma nem sempre é, sobretudo, idêntica a si mesma” (FOUCAULT, 2004 [1984], p. 7), rechaça a concepção essencialista ou fundamentalista do sujeito, uma vez que o autor desenvolve em sua arque-genealogia uma concepção socio-histórica de forma-sujeito, argumentando que esta entidade "aparece não como instância fundadora, mas como efeito de uma constituição” (FOUCAULT apud CASTRO, 2016, p. 407-408).

Desse modo, podemos asseverar que, enquanto sujeitos situados, marcados por inumeráveis contingências do plano histórico e ideológico, estamos inscritos em uma trama complexa de relações sociais que, dentre outras estratégias de organização de seus quadros normativos, determina possibilidades de subjetivação inteligíveis, inclusive em termos de corpo e gênero, graças ao exercício contínuo de delimitação dos modos de subjetivação ininteligíveis e das fronteiras entre ambos. Grosso modo, "em nossa sociedade, a norma que se estabelece, historicamente, remete ao homem branco, heterossexual, de classe média urbana e cristão"(LOURO, 2000, p. 9). Os sujeitos não são significados no interior dessas categorias normativas determinadas compulsoriamente são subjugados, posicionados em um lugar abjeto ${ }^{4}$, sob o signo da precarização de suas condições de existência e de sua exposição a inumeráveis vulnerabilidades (e, por isso, inumeráveis possibilidades de resistência), desde o corpo, como ainda

\footnotetext{
${ }^{4}$ Segundo Júlia Kristeva (1982, p. 4), o abjeto é, também, o que perturba a identidade, o sistema, a ordem. No pensamento butleriano tal conceito é retomado e ressignificado, "caracterizando mais genericamente uma das pré-condições da subjetivação pressuposta nas práticas disciplinares que rejeitam (e, talvez por isso, incorporam) outras modalidades de ser; uma vasta zona repudiada, pois se as práticas regulatórias exigem determinados tipos de identificação, fazem-no demarcando uma zona inabitável" (DEMETRI, 2018, p. 53, grifo do autor).
} 
é caso daquelas/es reconhecidos socialmente através das categorias "mulher", "negra/o" "homossexual", "transexual", "travesti", "refugiada/o" e "pobre", dentre outras identificações contextual e interseccionalmente produzidas.

A constatação desse funcionamento que produz a exterioridade da norma, sua transgressão, como elemento a partir do qual os termos da norma, a normalidade, se fundam corresponde ao que Derrida nomearia como "exterioridade constitutiva". A partir disso, Hall (2000, p. 100), nos termos próprios de suas discussões, afirma que "é apenas por meio da relação com o Outro, da relação com aquilo que não é, com precisamente aquilo que falta, com aquilo que tem sido chamado de seu exterior constitutivo, que o significado positivo de qualquer termo pode ser construído”. Assim, tais asserções nos levam a pôr em evidência que os processos de produção de tais sujeitos, esses, significados do lado de fora da norma, os quais "representa[m], sem dúvida, a alteridade do mal que vem afetar e infectar o dentro, irrompendo nele imprevisivelmente” (DERRIDA, 1997, p. 80, alteração nossa), se dão mediante políticas de constante enfrentamento, desnaturalização e suspeição face às diferentes estratégias com as quais transgressivamente negociam, ainda que pela via de uma relação de desobediência, a qual, inescapavelmente reconhece a existência da norma, ainda que mediante de sua deslegitimação ou rasura.

As concepções essencialistas de gênero, baseadas "no modelo expressivo da identidade tributário do Iluminismo e da Filosofia cartesiana e constantemente reatualizado pela medicina, pelo direito, pela religião, pela filosofia, pela sociolinguística quantitativa, pela sociologia das minorias" (BORBA, 2014, p. 447) e as relações de poder das quais emergem têm implicado consequências que ainda se mostram problemáticas no enquadre social vigente. Referimo-nos aqui, de forma mais direta, desde os modos de organização social do ocidente ao modelo de gestão de políticas públicas em saúde e educação, quase sempre erigidos sobre binarismos e obsessões classificatórias, os quais convertem-se em matrizes de (re)produção da violência subjetiva exercida pelo poder colonial, capitalista, racista, eurocêntrico, sexista, misógino e cisheteronormativo, que relega a multiformes condições de abjeção aquelas/es que são posicionadas/os do lado de fora de seus modelos identitários higiênicos e hegemônicos, aquelas/es que são classificados como queer.

A exemplo do que reflete Moita Lopes (2013, p. 242), no ponto de virada de seus estudos, ao passar de uma perspectiva soioconstrucionista de identidade para uma filiação mais efetiva a perspectivas queer, como as aqui apresentadas, cremos que com tais teorias "abraçamos uma posição de desmoralização de qualquer projeto identitário entendido como natural, dado ou legítimo". Ejustamente a não naturalidade desses projetos identitários têm como fundamento a linguagem, o caráter performativo do discurso e os efeitos de estabilidade/instabilidade que dele/nele podem emergir. A essa dimensão dedicamos nossas reflexões na seção a seguir.

\section{LINGUAGEM, PERFORMATIVIDADE E PODER: REGULAÇÕES E DESESTABILIZAÇÕES DE/NO GÊNERO}

Na origem de uma compreensão performativa de linguagem está, inegavelmente, o pensamento do filósofo John L. Austin (1976). Ao abandonar o recurso retórico de que se valeu até certo ponto de suas argumentações, segundo o qual na linguagem coexistiriam "enunciados constatativos", os quais apenas descreveriam a realidade, e "enunciados performativos", aqueles que realizariam aquilo que enunciam, Austin passa a sustentar que toda a linguagem é performativa. Assim, afirmar o caráter performativo da linguagem implica dizer que todo uso da linguagem faz, realiza, produz as realidades as quais enuncia. Dessa visada, construtos tomados como dados, naturais, essenciais e estáveis passam agora ao campo das contingências, por isso, passíveis de serem questionados, sobretudo acerca de seu processo de produção mediante a ação de tal performatividade e dos efeitos de uma "metafísica substância" da qual gozam, como se refere Butler (2003, p. 42), também em função da referida propriedade da linguagem.

No horizonte das questões abertas por tais asserções, podemos pensar: se dizer é fazer, então, como a linguagem faz identificações de gênero? E mais, como a linguagem produz corpos e corpos generificados? Essas questões foram aventadas, em certa medida, por Butler (2003), ao se deparar com os escritos de Austin. São também essas as questões norteadoras desta seção e que serão discutidas transversalmente ao refletirmos sobre linguagem, identidade e corpo. 
Apesar da já referida distinção apresentada por Austin (1976) entre a natureza dos atos de fala constatativos e dos performativos, o que chama a nossa atenção é o fato de que enunciados performativos são também aqueles cujas condições de existência não podem ser verificadas a partir do princípio lógico-formal da "verdade", como critério predominante nas considerações sobre linguagem da filosofia analítica da época. Na visão de Pennycook (2007) acerca de tal operação intelectual austiniana, a relevância de os atos de fala performativos não estarem vinculados às condições de verdade, ou seja, de apenas poderem ser apreciados segundo condições de felicidade, é que, dessa forma, esses enunciados têm sua natureza vinculada diretamente à eficácia de sua própria enunciação: se obtém êxito em realizar o que enunciam.

As condições de felicidade não dependem de fatores estritamente linguísticos para se realizarem. Apesar dos esforços retóricos de Austin (1976) em descrever linguísticamente a estrutura dos enunciados performativos, objetivando justamente apontar o fracasso implicíto a tal empreendimento, assinala que essa impossibilidade advém da variedade infinita de categorias que um performativo poderia assumir, haja vista suas condições de felicidade excederem o plano do linguístico, estando relacionadas a fatores contextuais indetermináveis de um ponto de vista abstrato e universal (como nas condições de verdade dos constativos), fora de situações reais de prática linguística. O performativo, na teoria austiniana, alcança as condições de felicidade quando encontra um conjunto de fatores contextuais adequados, como seguir o procedimento convencional, possuir o direito à palavra que deve ser proferida nas circunstâncias certas e, por conseguinte, obter o efeito certo.

Na esteira dessas ideias, é no trabalho crítico de Derrida (1991) em torno das perspectivas de Austin (1976) que o performativo tem sua felicidade - seu efeito de produzir o que enuncia - atrelada às ideias de repetição/alteração, identidade/diferença. Assim, na interpretação derridiana, as noções de citabilidade e de iterabilidade 5 são acionadas com vistas a desconstrução de conceitos ligados à noção de sujeito (um certo valor de presença) e de contexto (em algum grau recuperável ou determinável) que, segundo ele, guardariam ainda alguma relação com perspectivas metafísicas ou teleológicas no pensamento austiniano. A questão para Derrida é se uma declaração poderia ser bem-sucedida ainda que sua formulação não repetisse um enunciado codificado, ou seja, para o autor, a questão está na (não) existência de um potencial performativo em enunciados que não são identificados em conformidade a um modelo iterável e, portanto, na possibilidade desse enunciado ser identificado na forma de uma citação. Como destaca Navarro (2008):

\footnotetext{
[...] o ato comunicativo, no caso da enunciação performativa da linguagem, vemos que as condições que tornam um ato comunicativo, no caso da enunciação performativa, teria que supor um processo diferente de uma mera transmissão de sentidos intencionais presentes na consciência do falante e, mais claramente ainda, diferente da representação de um "estado de coisas" previamente determinado. A performatividade corresponde a outra função da linguagem, a de "fazer as coisas com as palavras" ou, como Derrida expressa, de "comunicar uma força pelo impulso de um marca". Uma força cujo objetivo característico, como mencionamos, deve ser completamente diferente do dos enunciados constativos. (NAVARRO, 2008, p. 46, tradução nossa.)
}

Nesse sentido, conforme amplamente posto nos desenvolvimentos recentes e interdisciplinares da perspectiva performativa da linguagem, as condições que levam os atos perforativos a atingirem sua felicidade são, definitivamente, não linguísticas. Assim, como aponta Pennycook (2007), o cerne da questão deslocou-se da natureza da relação entre as estruturas linguísticas e seus efeitos para pensar como, a partir de quais complexos processos, é que as palavras têm efeitos. Em Butler (2003), os efeitos de tal compreensão abarcam, inclusive, sua compreensão dos processos subjetivos, entendendo a categoria sujeito enquanto um produto performativo, um efeito situado de discursos. Assim, concordamos com Salih (2017), no sentido de que, no pensamento butleriano, o sujeito é um sujeito-em-processo que é construído no discurso pelos atos que executa.

\footnotetext{
${ }^{5}$ No pensamento derridiano, citabilidade e iterabilidade são propriedades dos signos, por isso, da linguagem, complexamente imbricadas. Se a primeira delas diz respeito, grosso modo, ao fato de que todo signo pode ser destacado, recortado de sua situação comunicativa, de seu contexto e da presença do sujeito enunciador (e de sua intenção) de origem, por isso, citado, a segunda alude a possibilidade de este ser repetido, iterado, na ausência desses mesmos elementos de origem, compondo assim indefiníveis novos contextos, numa relação contínua de repetição e alteração, identidade e diferença. Para uma discussão mais detida dessa questão ver Santos (2014).
} 
Nessa visada, podemos entender a performatividade, à luz de Butler (1997), como sendo a maneira pela qual se realizam atos identitários em uma contínua série de performances sociais e culturais. A performatividade é a performance de atos prescritos. Pennycook (2007) diz que a performatividade se refere às condições subjacentes que tornam a performance possível ou ao que faz uma determinada performance acontecer ou não.

Nesse sentido, pensando com Moita Lopes (2013), validamos que o performativo se configura a partir de performances repetidas, enquanto a performatividade seria a possibilidade de inaugurarmos performances inovadoras. A performance, então, pressupõe a existência de um sujeito que a põe em prática, enquanto a performatividade não o pressupõe, o que não significa que ele não existe, mas, sim, que não é dado (SALIH, 2017). Pensando desse prisma, as identificações de gênero, portanto, são compreendidas como produto de uma sequência de atos, mas que não existe um ator preexistente que pratica esses atos, não existe nenhum fazedor por trás do feito.

Os efeitos de identidade são, dessa perspectiva, produzidos performativamente, ou seja, não são instâncias dadas previamente, logo, não preexistem aos discursos. Assim, as identidades são processos negociados, disputados, construídos por e no discurso, no interior de quadro normativos fixos. Como nos alerta Silva (2017, p. 65):

[...] pensar que a identidade é não um dado interno ao "sujeito", mas efeito instável e continuamente em vias de implementação nas infindáveis performances (ações) que realizamos, nos mais diversos contextos, sobretudo, por meio da linguagem, dos discursos, inverte a dinâmica de compreensão da questão identitária e subjetiva. Não há identidade anterior ao uso, assim como não há sujeito anterior à linguagem, ao discurso. É na ação que ambas as realidades se constituem e produzem efeitos de estabilidade que geram a ilusão de univocidade, delimitação estanque, estabilidade e naturalidade.

Do ponto de vista das relações de poder imiscuídas nos processos performativos, o indivíduo é fabricado minuciosamente, segundo uma tática das forças e dos corpos, trazidas à existência por meio da produção discursiva. Trata-se, no que tange à produção de efeitos identitários de gênero e corpo, de um poder disperso e cotidiano, que se exerce em um campo de interações. Há uma ação violenta nos efeitos de poder que está intrinsecamente ligada à arbitrariedade dos elementos do conhecimento, é preciso entender como se relacionam mecanismos de coerção e elementos do conhecimento (FOUCAULT, 2009 [1969] p. 53). Na produção do saber, por meio da qual o mundo é construído e torna-se conhecido, há uma institucionalização das relações de forças que realizam escolhas determinadas por uma suposta naturalidade e imparcialidade. Segundo Foucault (2009 [1969], p. 52), "[...] nada pode existir como um elemento do conhecimento se, por um lado, não se conformar a uma série de regras e características constrangedoras [...], e por outro, se não possui os efeitos de coerção".

Esse modo como o poder funciona nos põe em uma condição na qual estamos sempre submetidos e sempre livres. Toda relação social guarda a possibilidade de uma relação de poder, assim como toda relação de poder é passível de mudança. O poder modela, a partir de dentro, os sujeitos, os corpos, as posições identitárias e de gênero, desde o início, e aparece como uma interdição posterior daquilo que ele mesmo causa, escamoteando assim o fato de tê-lo causado. É uma forma de poder que faz dos indivíduos sujeitos (FOUCAULT, 2006 [1994]).

A performatividade por meio da qual se constroem as identidades de gênero permite a cristalização do gênero, proporcionando a aparência de que ele esteve sempre presente. O gênero, no entanto, é um processo que não possui origem nem fim. O gênero é sempre um fazer, "é a estilização repetida do corpo, um conjunto de atos repetidos dentro de um quadro regulatório altamente rígido que se solidifica ao longo do tempo para produzir a aparência de uma substância” (BUTLER, 2003, p. 33). Gênero é, portanto, um efeito de atos de fala, cujo perigo está em sua aparente naturalidade, uma vez que esta produz uma estrutura binária e hierarquizada. Esse efeito é produzido, mantido, recusado e modificado nos atos de fala disponíveis em nossa sociedade. Dizer que o gênero é produzido performativamente implica afirmar que não há uma relação de equivalência compulsória entre os significados culturais atribuídos ao corpo de alguém e as performances de gênero desempenhadas. Assim, fica claro que gênero não é uma 
expressão de uma propriedade essencial do corpo, ou seja, "não há identidade de gênero por trás das expressões de gênero; essa identidade é performativamente constituída, pelas próprias ‘expressões’ entendidas como seus resultados” (BUTLER, 2003, p. 48).

Conforme o pensamento de Butler, não assumimos a negação da existência da materialidade do corpo, como algumas perspectivas críticas de sua obra tendem a apontar, mas rechaçamos que seja dado a este corpo um status ontológico. Salih (2017) sintetiza de forma clara as acepções de Butler sobre o corpo, ao afirmar que, no construto teórico butleriano, assume-se a existência de um corpo físico anterior à identidade, no entanto, a percepção e o corpo são discursivamente construídos por meio do tabu, da exclusão e da interdição - procedimentos de coerção discursiva elencados por Foucault em A ordem do discurso. O corpo não é um fato do mudo, um fato da natureza, mas é produzido por discursos.

No sentido de uma compreensão complexa e progressiva da natureza discursiva da realidade, dos efeitos de gênero e dos corpos, vale ressaltar que, na chamada virada linguística nas Ciências Humanas passamos à noção de que a linguagem nos produz enquanto sujeitos, mas é a chamada virada somática que nos leva totalmente de volta à noção de incorporação, de encarnação discursiva de um corpo-efeito. Tal virada, cunhada por Pennycook (2007), direciona nossa atenção para os modos pelos quais o corpo age na linguagem. A importância da virada somática reside em pelo menos três dimensões: $a$ ) na reação contra o idealismo logocêntrico do pós-estruturalismo; $b$ ) na recuperação dos domínios do ser que foram extirpados pela filosofia racionalista; $c$ ) na dimensão política, principalmente a feminista, que exige explicar nossa presença física. Para Pennycook (2007), é preciso questionar o papel que se dá ao discurso após a virada linguística, não questionando o seu poder e importância, mas reconhecendo que ele deve ser admitido como parte do desempenho transmodal. O uso da linguagem deve ser concebido de forma associada ao corpo.

Podemos dizer, por fim, que somos produtos da performatização de repetidas performances que executamos dentro dos rígidos quadros de poder nos quais estamos inseridos. É por intermédio da linguagem que fazemos, que produzimos, que existimos. Corpo e identidade se constroem por meio da linguagem e se particularizam através das inscrições discursivas contingenciais e situadas que lhe são atribuídas.

\section{UMA EPISTEMOLOGIA TRANSGRESSIVA DE SI: SUBVERSÕES CORPORAIS E GENÉRICAS DE UMA "BIXA TRAVESTY"}

As performances discursivas (doravante PD) aqui analisadas foram produzidas no contexto da entrevista escrita publicada em 8 de agosto de 2017 pela versão online da revista CULT e mediada pelo jornalista Marcelo De Trói. A CULT é uma revista mensal que aborda temas, em geral, relacionados à arte, cultura, filosofia, literatura e ciências humanas. Muitos de seus textos são escritos por intelectuais vinculados a alguma universidade brasileira, bem como jornalistas com carreiras estabelecidas. O objetivo da revista em sua versão online, segundo exposto em seu sítio na internet, é ampliar o acesso do grande público a temas que por muito tempo ficaram presos aos centros acadêmicos (UOL, 2018).

A entrevista intitulada Ficou insustentável fingir que nós não existimos, foi concedida por Linn da Quebrada, que em seu site (LINN DA QUEBRADA, 2018) apresenta a si mesma enquanto uma "artista multimídia” e "bixa travesty" que encontrou na música uma forma de lutar para quebrar paradigmas sexuais, de gênero e de corpo aos quais esteve submetida ao longo de sua história pessoal e que marcam a sociedade brasileira em geral. A atriz, cantora e compositora, inova e incomoda ao destoar do estereótipo normativo de mulher trans com "passabilidade" 6 .

\footnotetext{
${ }^{6}$ Termo utilizado usualmente para designar pessoas trans e travestis ditas mais conformadas à norma corporal cisgênera, as que atenderiam a padrões corporais de feminilidade e beleza, ou seja, que facilmente se "passariam" por pessoas cis, não sendo prontamente identificadas como trans ou travestis.
} 


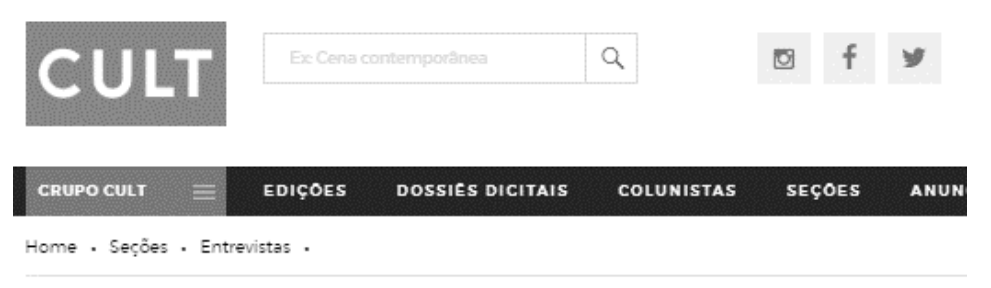

\section{Linn da Quebrada: Ficou insustentável fingir que nós não existimos}

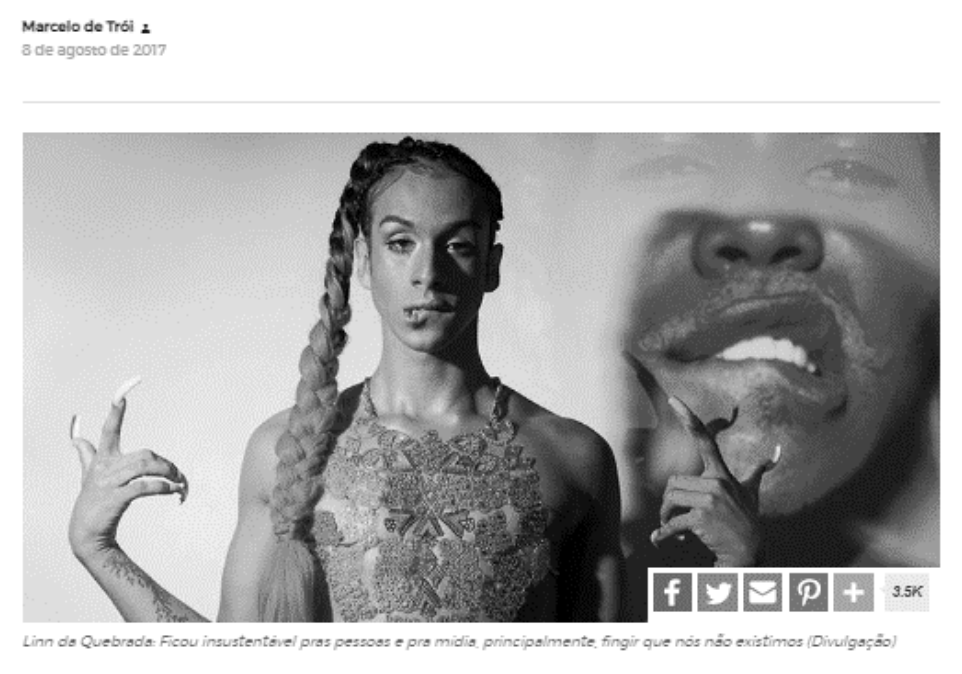

Figura 1: Entrevista de Linn da Quebrada à Revista Cult

Fonte: Trói (2017)

Estreando no mercado musical em 2016, com músicas como "Enviadescer", "Mulher" e "Pajubá”, Linn da Quebrada está entre as artistas mais relevantes do cenário musical queer, no Brasil e no mundo. Sua aparição coincide com um momento social e político em que ascendeu a um lugar de pauta do dia, em muitos nichos culturais, tratar de tabus e desconstruir estereótipos, no seu caso, com um estilo mordaz e sarcástico de crítica à norma, o que lhe é bem particular.

Do ponto de vista metodológico, nosso trabalho de análise filia-se àquelas perspectivas de inspiração qualitativa e pós-estruturalista, uma vez que focaliza "as coisas em seus cenários naturais, tentando entender ou interpretar os fenômenos em termos dos significados que as pessoas a eles conferem" (DENZIN; LINCOLN, 2006, p. 17) e compreendem o trabalho de interpretação de dados gerados não como "[...] uma busca neutra por verdades subjacentes aos dados de análise, mas está centrada justamente nos múltiplos significados que estão disponíveis nas práticas linguísticas para a construção da realidade” (SILVA, 2017, p. 101).

Desse modo, afastando-nos do discurso da objetividade e neutralidade técnicas de paradigmas positivistas de pesquisa, os quais tomam seus dados de análise como elementos dados e prontamente disponíveis à observação da/o pesquisadora/r, ruptura característica da Linguística Aplicada na modernidade recente (MOITA LOPES, 2013), assumimos aqui uma perspectiva crítica e engajada, como assinalado na introdução deste trabalho, a qual testemunha a implicação dxs pesquisadorxs com o "objeto" que integram a pesquisa. Nesse caso, uma vez que investigamos dados gerados a partir de material textual escrito, o que poderia parecer uma arbitrariedade, demérito em termos de pesquisa positivista, parece-nos uma postura amplamente abalizada no intento de produzir, neste trabalho, uma "[...] prática inteligibilidade individual do significado construído socialmente [...]” (MOITA LOPES, 1994, p. 331).

À luz de tais premissas metodológicas e das perspectivas teóricas sobre a linguagem validadas neste trabalho, tomamos as porções de texto selecionadas do todo da entrevista, consideradas as especificidades desse gênero do discurso ${ }^{7}$, como performances

\footnotetext{
${ }^{7}$ A exemplo dessas especificidades que, mesmo consideradas em sua relevância, não serão focalizadas neste trabalho em razão de seus objetivos e das limitações que a extensão de um artigo nos impõe, está o encadeamento interativo no par pergunta-resposta em suas relações dialéticas e de "efeito gatilho". Desse modo,
} 
discursivas situadas, elaboradas no influxo da produção de atos de fala que significam implicados na complexidade de fatores situacionais, subjetivos, sociais, políticos, ideológicos, ad infinitum. Assim, passemos às análises:

\section{PD1}

CULT - Você, como ex-Testemunha de Jeová, que se converteu para a arte transviada, disse ter marcas no corpo sobre esse passado e pensei ser algo similar à violência sofrida pelos índios com as missões. Que marcas são essas?

LQ - Qualquer que seja nossa trajetória, o corpo carrega memória. Uma das várias marcas que o meu corpo carrega dessa época está relacionada à culpa, uma construção do sagrado, do profano, do pecado, que acabou demorou pra ser desconstruída. Tem a ver com culpa, pertencimentos, perceber o meu corpo como sendo errado, como se eu tivesse de abrir mão de mim mesma para poder existir, para pertencer àquela comunidade.

Em PD1, a ativista alude aos efeitos que as trajetórias dos sujeitos, que são trajetórias discursivas, inscrevem no corpo, produzindoo, conformando-o, evidenciando a operação de uma memória que não se mostra estática, mas alude a um memorial, no sentido de um passado de algum modo significante e inscrito no presente, do aqui e agora, e no devir. Desse modo, instaura sentidos que compreendem um corpo físico, material, somático, significado ao ser atravessado por determinados discursos, regulações e suas trajetórias.

Assim, tal instância discursiva do corpo pode ser explicitada por intermédio da natureza somática da violência exercida pelas fronteiras das categorias identitárias várias, a exemplo de raça, gênero, sexualidade, classe, no interior das quais os corpos são produzidos e passam a gozar de maior ou menor inteligibilidade social em função de sua adequação, sempre contingente, aos limites das referidas categorias, o que fica saliente com a constatação como se eu tivesse de abrir mão de mim mesma para poder existir, para pertencer àquela comunidade.

As marcas que constroem o corpo de Linn da Quebrada, como posto em sua narração performativa de si, não dizem respeito a marcas necessariamente físicas. Esse corpo marcado ao qual ela se refere foi feito/produzido como sendo um corpo culpado, através da repetição de atos de fala performativos produzidos pelo discurso do religioso. Esses atos de fala produziram o que pode ser lido como sendo um corpo, em certo momento, clivado, cindido, disputado pelo discurso da dicotomia sagrado/profano. Desse modo, em sua performance discursiva, os sentidos da culpa, gerada pela transgressão às normas sexo-genéricas estabelecidas no interior do discurso fundamentalista cristão, ganham dimensão somática, uma vez que estas passam a integrar sua corporeidade como uma memória presentificada, que é carregada não pelo corpo, mas no corpo, estilizado, produzido, significado no interior de um sistema de regulação de gênero e sexualidade da matriz binária e cisheteronormativa.

Mediante a rememoração na qual o jornalista traz à tona as vivências da ativista enquanto Testemunha de Jeová ${ }^{8}$, gatilho de sua performance discursiva, a travesti produz sentidos que apontam para a produtividade das estilizações nas quais seu corpo se produziu no contexto religioso, estilizações de pureza e santidade das quais afirma ter tido dificuldade de se desvencilhar, dificuldade de desaprender, desconstruir. Tal produtividade da norma, nesse caso da cisheteronorma imiscuída na religião, é justamente sua abertura para a paródia, para a possibilidade de transgressão, para uma repetição (citação) que a transgride, a assume sob rasura e revela, assim, seu caráter performativo, ou seja, não essencial ou ontológico.

Desse modo, as estilizações que hoje o corpo em trânsito, rasurado, da ativista "terrorista de gênero" performatizam não apagam os efeitos das trajetórias discursivas produzidas pela matriz normativa do religioso em si mesma, mas, ao contrário, são essas marcas, narradas pela travesti sob a performatividade dos itens indexicais culpa, pertencimentos, perceber meu corpo como sendo errado que,

focalizaremos nossos esforços interpretativos nas respostas dadas pela ativista, uma vez que nelas situam-se as performances discursivas que nos interessam compreender neste artigo.

${ }^{8}$ Grupo religioso de confissão cristã, de abrangência internacional, conhecido por suas posições fundamentalistas em temas como a doação de sangue e aqueles da ordem da moral sexual e das experiências de gênero. 
numa apropriação queer, demonstram que corpo e gênero, ou melhor, que os efeitos identitários que essas instâncias possam gerar são sempre de cunho paródico e nunca uma repetição, no sentido mimético da palavra.

Em continuidade às ideias elaboradas, a Linn da Quebrada fala no texto 2 sobre o corpo como uma forma de ação e resistência.

PD2

CULT - O que é terrorista de gênero?

LQ - Eu lancei essa ideia porque eu acho que a violência da sociedade com alguns corpos, corpos como o meu, pretos, transviados, de quebrada, essa violência está posta. É necessário responder também com terror, com agressividade, colocando o meu corpo como arma, como protesto, manifesto, como pólvora diante desse sistema que é violento cotidianamente.

Ao buscar responder à pergunta do entrevistador que a inquire acerca de uma autonomeação correntemente utilizada pela ativista, a qual se autodesigna como "terrorista de gênero", a ativista, em sua performance discursiva produz seu corpo como significado em conflito com a norma, como parte daquela multidão de corpos queer a qual fez referência Preciado (2011), posicionados normativamente na exterioridade das fronteiras de inelegibilidade, corpos lidos como não-humanos pelos modelos hegemônicos de identidade na sociedade brasileira, mas que, embora violentados, não se constituem "um dado passivo sobre o qual age o biopoder, mas antes a potência mesma que torna possível a incorporação prostética dos gêneros" (PRECIADO, 2011, p. 14). Ao produzir uma identificação, uma aliança de seu corpo travesti com outros corpos pretos, transviados, de quebrada, os quais são posicionados no local social e político da abjeção e da precarização, a ativista alude a essa potência de transgressão, em resposta da violência estrutural contra esses corpos, essa multidão de corpos na qual inclui o seu.

Nesse sentido, sua performance discursiva produz sentidos que apontam para a potência da abjeção, para o que podem os corpos e as performances identitárias em conflito paródico com a norma diante da ameaça da violência. Assim, tornam-se compreensíveis os sentidos desse "terrorismo de gênero", uma potência de ameaça performativa contra os diversos processos de exclusão aos quais estão submetidos, dentre eles os da ordem da visibilidade, a exclusão das possibilidades estéticas e políticas desses corpos e do que eles podem. Assim, em sua performance discursiva denuncia os efeitos de estabilidade e fixidez que algumas posições identitárias passam a gozar e como tal processo está implicado na base das dinâmicas de hierarquização das vidas e dos corpos.

No influxo da produção desses sentidos, ao significar performativamente seu próprio corpo, um corpo travesti, transviado, queer, como uma forma de ação ante a violência que está posta, a ativista reconhece que a guerrilha na qual está inserida e armada não é apenas de ordem material, como não o é o corpo, mas possui uma dimensão amplamente discursiva e somática: uma luta de/por/entre inelegibilidades corporais e identitárias. Assim, seu corpo - o meu corpo como arma, como protesto, manifesto, como pólvora diante desse sistema que é violento cotidianamente - é performativo e produz performatividade, ou seja, age sobre a realidade produzindo novas versões de si mesma, num exercício epistemológico transgressivo de si, justamente por estar situada no interior de quadros normativos bastante regulados, a exemplo dos padrões de corpo, gênero e sexualidade caracterizados pelo binarismo, pela branquitude e pela cis-hetero-normatividade compulsória. 
PD3

CULT - O corpo da travesti, das pretas, índios, corpos não conformados, serão enfim corpos que importam?

LQ - Esses corpos, primeiramente, precisam importar para nós. Por isso acho importante essa formação de rede de apoio emocional, psicológica, econômica e até mesmo sexual. É olhar para nós, umas e outras, com desejo, sem sermos reféns do olhar masculino. O macho está tão bem protegido e situado somente porque os homens admiram outros homens. Ao feminino, independente onde ele esteja, eles só reservam servidão e sexo.

É nesse sentido que, como emerge da PD3, Linn da Quebrada, ao ser perguntada sobre a importância de outros corpos que fazem parte da multidão queer a ativista faz alusão a necessidade de identificação e de aliança performativa entre esses corpos, formando o que ela nomeia como rede de apoio emocional, psicológica, econômica e até mesmo sexual. Essa aliança é performativa no sentido de a "fusão" desses corpos e suas pautas e demandas ser capaz de produzir uma ação política coletiva diante da condição de precariedade comum à qual estão submetidos, o que na performance discursiva da ativista irrompe com a deslegitimação das normas corporais e sexo-genéricos que circunscrevem e precarizam a vida dos corpos queer, significadas em sentidos como o olhar masculino ou $o$ macho.

É justamente dessa solidariedade performativa entre corpos abjetos que a ativista identifica as posições identitárias hegemônicas que ameaçam as possibilidades múltiplas de realizações subjetivas em uma profusão crescente de corpos e gêneros: a posição hegemônica do macho, como patamar máximo de estabilidade e do gozo de prestígio e direitos simbólicos, sociais e políticos autolegitimados. Tal posição identitária é, ainda, construída como modelo e categoria-limite a qual corpos, gêneros e identidades desviantes devem compulsoriamente ser conformadas, evidenciando que "[...] não há gênero sem essa reprodução de normas que corre o risco de desfazer e refazer as normas dominantes de maneiras inesperadas, abrindo a possibilidade de refazer a realidade de gênero diante de novas linhas" (BUTLER, 2017, p. 38).

\section{COSIDERAÇÕES FINAIS}

Reconhecer que o potencial performativo da linguagem engendra a produção de processos sociais, políticos e culturais, a exemplo da elaboração e do reconhecimento das categorias corpo e gênero, ainda que em escalas locais, rompe com cartografias ideológicas calcadas no essencialismo e numa visão fixista das estruturas sociais, as quais, ao nosso ver, são reelaboradas, dialeticamente, em cada prática discursiva situada. Assim, passa a ser a suspeito desde a origem o estatuto comum a toda e qualquer aparência de fixidez, delimitação e estabilidade, a exemplo do modo como figuram as identidades nas grandes narrativas coloniais e nas práticas de uma ciência de cariz modernista.

Atingidas por essa visão, as fronteiras das categorias identitárias nas quais os corpos e os gêneros, em sua complexidade, são significados estão indefinidamente passíveis de alargamentos, flexibilizações, desterritorializações estratégicas em função da reivindicação de legitimidade e do direito à existência viável, a exemplo daquelas apresentações de corpo e gênero dissidentes das normas racistas e binárias que se organizam em assembleias performativas, sejam físicas ou virtuais, as quais "[...] põem em cheque a matriz primeira do poder, o primeiro registro de inscrição/ relação de poder/sujeição na experiência social e na vida do sujeito, as designações sociais de sexo e gênero" (SILVA, 2017, p. 81).

Nesse sentido, cremos que a partir da compreensão da produção de significados sociais em microeventos interacionais situados, a exemplo das performances discursivas queer da terrorista de gênero Linn da Quebrada, aqui analisadas, tensões e desestabilizações podem ser produzidas na aparente homogeneidade das narrativas que gozam de legitimidade para significar compulsoriamente corpos e gêneros, a exemplo das grandes e tentaculares narrativas religiosas e do Estado. Assim, "[...] seus corpos são, portanto, discursos, textos, signos de resistência em riste" (SILVA, 2017, p. 81). 
Desse entendimento é que emerge a necessidade de reivindicar uma produção do conhecimento, inclusive em Linguística Aplicada, que esteja comprometida com o atual movimento de "insurreição de saberes subjugados" (FOUCAULT, 1980, p. 81, tradução nossa.), identificados como "[...] todo um conjunto de saberes que foram desqualificados como inadequados para sua tarefa ou insuficientemente elaborados [...]" (FOUCAULT, 1980, p. 82, tradução nossa.), a exemplo de epistemologias transgressivas queer, travestis, pretas, viadas, sapatão e quantas mais formas outras de produção de saberes localizados, significados desde os corpos e suas contingências, tenham sido interditadas ou desconsideradas pela academia e seu cientificismo cartesiano historicamente excludente, mesmo quando afirmava produzir conhecimento sobre esses sujeitos interditados.

Como uma das consequências últimas de assumirmos o caráter performativo da linguagem, está a assunção de que todos os atos de fala, implicados nas mais diferentes performances discursivas da vida cotidiana, são politicamente implicados e constituem uma esfera de responsabilidade sobre esses dizeres e seus efeitos na vida concreta daquelxs sobre os quais agem, direta ou indiretamente. Ora, se há um campo aberto ao ativismo e às reivindicações de condições de vida dignas para quaisquer grupos sociais precarizados, pelas razões aqui discutidas, é a linguagem a primeira arena na qual tais batalhas serão encampadas.

\section{REFERÊNCIAS}

AUSTIN, J. L. How to do things with words. 2.ed. Oxford: Oxford University Press, 1976.

BENTO, B. O que pode uma teoria? Estudos transviados e a despatologização das identidades trans. Florestan, ano 1, n. 2, p. 46-66, nov. 2014.

BORBA, R. A linguagem importa? Sobre performance, performatividade e peregrinações conceituais. Cadernos Pagu, n. 43, p. 441474, jul./dez. 2014.

BORBA, R.; LOPES, A. Escrituras de gênero e políticas da différrance: imundície verbal e letramentos de intervenção no cotidiano escolar. In: SENALE, 7., 2016, Pelotas. Anais... Pelotas: Linguagem \& Ensino, 2018. p.241-285.

BUTLER, J. Problemas de gênero: feminismo e subversão da identidade. Tradução de Renato Aguiar. Rio de Janeiro: Civilização Brasileira, 2003.

BUTLER, J. Excitable speech: a politics of the performative. London: Routledge, 1997.

CASTRO, E. Vocabulário de Foucault - um percurso pelos seus temas, conceitos e autores. Tradução Ingrid Muller Xavier. 2. ed. Belo Horizonte: Editora Autêntica, 2016.

DENZIN, N. K.; LINCOLN, Y.S. O planejamento da pesquisa qualitativa: teorias e abordagens. Tradução Sandra Regina Netz. Porto Alegre: Artmed, 2006.

DEMETRI, F. Judith Butler: a filósofa da vulnerabilidade. Salvador: Devires, 2018.

DERRIDA, J. A farmácia de Platão. 2.ed. Trad. de Rogério Costa. São Paulo: Iluminuras, 1997.

DERRIDA, J. Limited Inc. Campinas: Papirus, 1991. 
FOUCAUlT, M. Two lectures. In: GORDON, C. (org.). Power/knowledge: selected writings, interviews \& other writings - 19721977. New York: Pantheon Books, 1980. p. 81-82.

FOUCAULT, M. A arqueologia do Saber. Rio de Janeiro: Forense Universitária, 2009 [1969].

FOUCAULT, M. A governamentalidade. Ditos e escritos IV - estratégias de poder-saber. Rio de Janeiro: Forense Universitária, 2006 [1994]. p. 281-306.

FOUCAULT, M. A ética do cuidado de si como prática da liberdade. In: Ditos \& escritos $V$ - ética, sexualidade, política. Rio de Janeiro: Forense Universitária, 2004 [1984]. p. 9-116.

HALL, S. A identidade cultural na pós-modernidade. Rio de Janeiro: DP\&A, 2000.

KRISTEVA, J. Powers of horror: an essay on abjection. New York: Columbia University Press, 1982.

LAGARES, X. C. Qual política linguística? Desafios glotopolíticos contemporâneos. São Paulo: Parábola, 2018.

LINN DA QUEBRADA. Sítio oficial da cantora na internet. Disponível em http://www.linndaquebrada.com/release. Acesso em: 22 set. 2018 .

LOURO, G. L. Pedagogias da sexualidade. In: LOURO, G. L. (org.). O corpo educado: pedagogias da sexualidade. 2. ed. Belo Horizonte: Autêntica, 2000. p. 7-34.

MISKOLCI, R. Teoria Queer: um aprendizado pela diferença. 3.ed. Belo Horizonte. Autêntica Editora. Universidade Federal de Ouro Preto, 2016.

MOITA LOPES, L. P. da. Gênero, sexualidade e raça em contextos de letramentos escolares. In: MOITA LOPES, L. P. (org). Linguística Aplicada na modernidade recente. São Paulo. Parábola Editorial, 2013. p. 227-247.

MOITA LOPES, L. P. Pesquisa interpretativista em Linguística Aplicada: a linguagem como condição e solução. Delta, v. 10, n. 2, p. 329-338, 1994.

NAVARRO, P. P. Del texto al sexo: Judith Butler y la perfotmatividad. Barcelona: Egales, 2008.

PENNYCOOK, A. Global Englishes and transcultural flows. London: Routledge, 2007.

PRECIADO, P. Multidões queer: notas para uma política dos “anormais”. Estudos Feministas, Florianópolis, v. 19, n. 1, p. 11-20, jan./abr. 2011.

RAMPTON, B. Continuidade e mudança nas visões de sociedade em Linguística Aplicada. In: (org.) MOITA LOPES, L. P da. Por uma Linguística Aplicada Indisciplinar. São Paulo: Parábola Editorial, 2016. p. 108-128. 
RESENDE, V. M. Direitos humanos para quem? Políticas públicas e gestão espacial da pobreza urbana em O Globo. Dossiê. Trab. Ling. Aplic., v. 57, n. 2, p. 616-644, maio/ago. 2018.

SALIH, S. Judith Butler e a teoria queer. Tradução e notas: Guacira Lopes Louro. Belo horizonte: Autêntica Editora, 2017.

SANTOS, K. C. Implicações da noção de sujeito na discussão da responsabilidade da fala. In: SILVA, D. N.; FERREIRA, D. M. N.; ALENCAR, C. N. Nova pragmática: modos de fazer. Campinas: Cortez, 2014. p. 287-307.

SILVA, D. C. P. Atos de fala transfóbicos no ciberespaço: uma análise pragmática da violência linguística. 2017. 200f. Dissertação (Mestrado em Letras) - Programa de Pós-Graduação em Letras, Universidade Federal de Sergipe, São Cristóvão, 2017.

TRÓI, M. de. Linn da Quebrada: Ficou insustentável fingir que nós não existimos. Revista Cult [Entrevista], 8 ago. 2017. Disponível em: https://revistacult.uol.com.br/home/entrevista-linn-da-quebrada. Acesso em: 26 set. 2018.

TRUJILLO, G. Pensar desde otro lugar, pensar lo impensable: hacia una pedagogía queer. Educ. Pesqui., São Paulo, v. 41, n. especial, p. 1527-1540, dez., 2015.

UOL. Revista Cult. Disponível em: http://revistacult.uol.com.br/home Acesso em 22 set. 2018.

\section{(1) $\circledast$}

